\title{
ANTI-CORRUPTION SPECIAL DETACHMENT, IS IT NECESSARY?
}

Corruption, being one of the powerful words, contains an astonishing power. Various ways to eradicate it - from changing the constitution to the formation of extra judicial institutions - failed; it is just strengthening its existence instead. Finally, the discourse of the formation of Anti-Corruption Special Detachment (Densus Tipikor) is rolled out by the Chief of Police. The discourse of this formation indicates that the existence of corruption rather than weakening can even be said to be increasingly rampant.

Corruption is not a single phenomenon; sometimes people get stuck in a system that is already corrupt and affect it, so that the person becomes corrupt. In other words, how a person becomes corrupt, not only because of the economic, moral, and group identity, but broader than. It is how their cultural values shape their attitude and behavior.

The problem that often arises from an anthropological perspective is that the definition of corruption that is followed by both international and governmental institutions is too narrow and is too concerned about the practice of illegality. As Sissener (2001) argues that judgment or what is seen as corruption varies from one context to another. Understanding of socio-cultural logic will show how corruption can be seen as an ambiguous phenomenon because of variations in social experience and cultural values.

There are a variety of socio-cultural practices that show that a single understanding and perception of corruption by the state, has created the instability and cultural structure of society. The experiences of various countries show it. A statement from Gupta (1995) is intriguing to be the subject of study. He declared, "The discourse of corruption varies a great deal from one country to another, dependent as it is on the particular historical trajectories and specific grammars of public culture". Based on this statement it can be argued that there are socio-cultural boundaries that indicate there is an acceptable behavior that is not the same in all contexts, but culturally more specific and mass-produced.

This view is not intended to legitimize corrupt behavior, but a more complete understanding of corruption from legal, political and socio-cultural aspects can be used to develop corruption eradication strategies. The formation of Anti-Corruption Special Detachment should not only be used as a political tool in response to the powerlessness of similar institutions in combating corruption. However, by looking at the fantastic amount of budget proposals, it is likely to compete in the handling of corruption, especially corruption conducted by the main institution that carried out corruption eradication. If that happens, then the chaos will re-appear which impact on the instability of integrity and state security.

Editor in Chief, 